\title{
Development of the Mexican Version of the Empathy Quotient
}

\author{
Ricardo Arturo Saracco-Álvarez, ${ }^{1}$ Ana Fresán, ${ }^{2}$ Víctor Rodríguez Pérez, ${ }^{3}$ Rebeca Robles-García, ${ }^{4}$ Raúl Iván \\ Escamilla Orozco, ${ }^{5}$ Leonila Rosa Díaz Martínez, ${ }^{6}$ Carlos-Alfonso Tovilla-Zárate, ${ }^{7}$ José Luis Olivares Neumann ${ }^{6}$
}

1 Clínica de Esquizofrenia, Instituto Nacional de Psiquiatría Ramón de la Fuente Muñiz, Ciudad de México, México.

2 Subdirección de Investigaciones Clínicas, Instituto Nacional de Psiquiatría Ramón de la Fuente Muñiz, Ciudad de México, México.

3 Programa de Salud Mental de la Clínica Especializada Condesa, Universidad Tecnológica de México-UNITEC, Ciudad de México, México.

${ }^{4}$ Dirección de Investigaciones Epidemiológicas y Sociales, Instituło Nacional de Psiquiatría Ramón de la Fuente Muñiz, Ciudad de México, México.

5 Jefatura de Clínicas de Especialidad, Instituto Nacional de Psiquiatría Ramón de la Fuente Muñiz, Ciudad de México, México.

- Servicio de Rehabilitación, Instituto Nacional de Psiquiatría Ramón de la Fuente Muñiz, Ciudad de México, México.

7 Universidad Juárez Autónoma de Tabasco, División Académica Multidisciplinaria de Comalcalco, Comalcalco, Tabasco, México.

Correspondence:

José Luis Olivares Neumann

Servicio de Rehabilitación, Instituto

Nacional de Psiquiatría Ramón de la Fuente Muñiz.

México-Xochimilco 101

Col. San Lorenzo Huipulco,

14370 Alcaldía Tlalpan,

Ciudad de México, México.

Phone: +52 $554160-5264$

Fax: +52 $554160-5000$

Email: jose300@gmail.com

Received: 19 June 2019

Accepted: 10 December 2019

Citation:

Saracco-Álvarez, R. A., Fresán, A., Rodríguez Pérez, V., Robles-García, R., Escamilla Orozco, R. I., Díaz Martínez, L. R. Tovilla-Zárate, C. A. \& Olivares Neumann, J. L. (2020). Development of the Mexican Version of the Empathy Quotient. Salud Mental, 43(2), 85-90.

DOI: $10.17711 / S M .0185-3325.2020 .012$

\begin{abstract}
Introduction. Empathy is defined as the ability or process to identify and understand other person's situation, feelings, and motives. These responses are essential for relationships and social behavior. Baron-Cohen et al. created the Empathy Quotient $(E Q)$, a scale explicitly designed to have a clinical application. The instrument evaluates three constructs of empathy and several studies around worldwide, but not in Mexico. Objective. To examine the psychometric properties and the factor congruence of the EQ in a community sample from Mexico City. Method. Cronbach's alpha coefficient and a correspondence factorial analysis was performed to test the relation between response options and factors from the Exploratory Factor Analysis 200 adults without Axis I disorders through the MINI, filled out the Spanish version of the short version (28-items) of the EQ. An exploratory factor analysis was performed while reliability was tested with Cronbach's alpha. In addition, correspondence factorial analysis and the factor congruence coefficient were determined. Results. Five items were eliminated from the original 28 -item EQ. From the 23 remaining items, only 16 were grouped in the three original proposed dimensions (cognitive empathy: 8 items, emotional reactivity: 4 items and social skills: 3 items), while one item showed communality with a different domain from the one originally proposed. Reliability was adequate (.82) as well as the congruence coefficients (.76 to .99). Discussion and conclusion. The EQ Mexican 16-item version is a good tool to assess empathy in a Mexican population.
\end{abstract}

Keywords: Validation, empathy, scale, congruence coefficient, mexican population.

\section{RESUMEN}

Introducción. La empatía es definida como la capacidad para identificar y comprender las situaciones, sentimientos y motivaciones de otra persona. Estas respuestas son esenciales para relaciones y comportamientos sociales. Baron-Cohen et al. crearon el cociente de empatía (EQ), una escala diseñada para tener aplicación clínica. El instrumento evalúa tres constructos de empatía y ha probado sus propiedades psicométricas con resultados adecuados en varios estudios mundiales, pero no en México. Objetivo. El propósito de este estudio fue examinar las propiedades psicométricas y la congruencia factorial del EQ en una muestra mexicana. Método. El alpha de Cronbach y el análisis factorial fueron aplicados para probar la relación entre las opciones de respuesta y los factores en 200 adultos sin diagnóstico, a través de la entrevista MINI. Se utilizó la versión corta en español del EQ y se realizó un análisis factorial exploratorio dónde se probó la confiabilidad con el alfa de Cronbach y se determinó adecuada correspondencia y congruencia factorial. Resultados. Se eliminaron cinco reactivos de la escala original de 28 reactivos. De los 23 reactivos restantes, solo 16 se agruparon en las tres dimensiones originales (empatía cognitiva: 8 reactivos, reactividad emocional: 4 reactivos y habilidades sociales: 3 reactivos) mientras que un reactivo mostró una comunalidad con un dominio diferente del original. La confiabilidad fue (.82), así como los coeficientes de congruencia (.76 a .99). Discusión y conclusión. La versión del EQ es una buena herramienta para evaluar la empatía en población mexicana.

Palabras clave: Validación, empatía, escala, coeficiente de congruencia, población mexicana. 


\section{INTRODUCTION}

Empathy is defined by Farrow (2007) as the ability or process to identify and understand other person's situation, feelings, and motives. This process implies a shared interpersonal experience to perceive and understand the emotional state and feeling with another person, and the ability to infer the origin of their emotional state. These affective and cognitive responses are essential for relationships and social behavior (Moore, Dev, Jeste, Dziobek, \& Eyler, 2015; Lamm, Batson, \& Decety, 2007).

Several information processes are relevant to empathy: perception and attending socially relevant stimuli, self-awareness, memory, emotion processing, executive control, perspective taking, selection of appropriate behavior, inhibition of proponent self-focus, reasoning, and Theory of Mind (ToM) (Farrow, 2007; Lamm et al., 2007). Therefore, three major clusters that include all the components of empathy have been described: a) cognitive capacity, b) affective response to understand emotional states, and c) the origin of feelings (self or others). These clusters are relevant in terms of theoretical conceptualization and for the objective assessment of the construct (Perry \& Shamay-Tsoory, 2013; Kim \& Lee, 2010).

Another important dimension of the concept of empathy is related to the difference between cognitive empathy and affective empathy. The first refers to the ability to perceive, interpret, infer, and explain the emotional state of another person, while the second process, affective empathy, involves inferring with another person's mental state, which overlaps with ToM. Both systems can function with a certain independence from one another and are necessary to display and adaptive social behavior (Moore et al., 2015; Zaki \& Ochsner, 2013; Pijnenborg, Spikman, Jeronimus, \& Aleman, 2013; Marsh, 2018).

The assessment of empathic abilities has a critical importance for mental health. The currently available scales, such as Hogan's scale, Mehrabian \& Epstein questionnaire, and Interpersonal Reactivity index or IRI (Davis, 1983; Leiberg \& Anders, 2006; Escrivá, Navarro, \& García, 2004) are instruments that allow for an approach to the objective evaluation of empathy, but have several limitations to be used in clinical settings (psychotic patients, autism, personality disorders), Baron-Cohen et al. $(2003 ; 2004)$ created the Empathy Quotient (EQ), a scale explicitly designed to have a clinical application and to be sensitive to the lack of empathy as a feature of psychopathology. The instrument evaluates three constructs of empathy and several studies around worldwide (Wakabayashi et al., 2006; Kim \& Lee, 2010; Preti et al., 2011; Berthoz, Wessa, Kedia, Wicker, \& Grèzes, 2008; Jankowiak-Siuda et al., 2017; Zhang et al., 2018) have tested its psychometric properties with adequate results. Until now, a validated self-report measure of empathy in Mexico is not available. The aim of the present study was to prove the psychometric properties of the EQ in a Mexican sample.

\section{METHOD}

\section{Participants}

Recruitment procedure included a non-probabilistic sampling approach: subjects from the general population of Mexico City who were available and willing to participate in the study were enlisted. After discarding any Axis I psychiatric disorder through the Mini-International Neuropsychiatric Interview MINI (Sheehan et al., 1998), a total of 200 adults were included. The sample included $124(62 \%)$ women and 76 men (38\%) with a mean age of 30.4 years $(S D=10.5$, range $18-64)$.

\section{Measurement and procedure}

The MINI, a brief structured interview, adapted for Central and South America (Sheehan et al., 1998) was used to exclude subjects with any Axis I psychiatric disorders according to the Diagnostic and Statistical Manual of Mental Disorders (4th ed., text rev.; DSM-IV-TR: American Psychiatric Association, 2000).

The Empathy Quotient (EQ) is a 60-item self-report questionnaire aimed at measuring empathy (Lawrence, Shaw, Baker, Baron-Cohen, \& David, 2004; Baron-Cohen, 2012). Twenty items are used as filler, so the original scale comprises 40 items for analysis. Each item is scored initially in a 4 - point agreement scale ranging from "strongly agree" to "strongly disagree". According to the sense of the item and the subject response, each item is then scored according to the magnitude of the empathic response, with 0 for a "non-empathic" response, and 1 for "slightly empathic" and 2 for a "strong empathic response". The original EQ has been reduced and validity and reliability proved by Lawrence et al. (2004). This version comprises 28 items arranged in three different empathy dimensions: cognitive empathy (11 items), emotional reactivity (11 items), and social skill (6 items); for the present study, we used the version developed by Lawrence et al. (2004).

Recruitment for the study began after the translation procedure was completed in accordance with the American Research Teams (Pan \& de la Puente, 2005). The EQ was first translated from English to Spanish by two independent translators and if any discrepancy arose, it was reviewed by an independent mental health professional and consensus was reached for an adequate language adaptation.

\section{Statistical analyses}

Analyses were performed with the 22.0 version of the SPSS statistical software. Skewness and kurtosis were used to test 
the normal distribution of the EQ 28-item scale proposed by Lawrence (2004). The procedures (Nunnally, 1994; Reyes-Lagunes \& García y Barragán, 2008) for testing the psychometric properties of the EQ-28 were done as follows: First, an item by item frequency analysis was performed to determine if all answer options were attractive and was followed by a discriminative analysis by means of Student t-tests (including extreme quartiles) where items with a non-significant value $(p>.05)$ were eliminated.

Then, an Exploratory Factor Analysis (EFA) with equamax rotation was performed. The equamax rotation was selected in view of the fact that subjects may report several EQ features concurrently. Items whose communality was higher than .40 were retained and allocated to factors, while those with a communality of less than .40 were excluded. After EFA, the internal consistency of the EQ dimensions and the total score were estimated with the Cronbach's alpha coefficient.

A correspondence factorial analysis was done to test the relation between response options defined as: a) $0=$ Non-empathic response, b) $1=$ Slightly empathic and c) $2=$ Strong empathic response, and the factors obtained from the EFA. Finally, we tested the congruence coefficient factor of our data with the factor loadings obtained by Lawrence et al. (2004), using the formula proposed by Wrigley and Neuhaus (1955) with $>.60$ coefficients considered as congruent.

\section{Ethical considerations}

The study protocol and procedures were approved by the Institutional Review Board of the INPRFM. All participants received a complete explanation of the nature and procedures of the study and those who voluntarily accepted to participate provided a written informed consent.

\section{RESULTS}

The 28 items of the EQ scale showed acceptable values of skewness and kurtosis, where none of the values was excessively out of range (skewness ranged from -.56 to 1.41 and kurtosis ranged from -1.52 to .85) except for item 1: "I can

Table 1

Exploratory Factor Analysis and psychometric properties of the EQ

\begin{tabular}{|c|c|c|c|c|}
\hline \multicolumn{2}{|c|}{ EQ Items } & \multirow{2}{*}{$\begin{array}{c}\begin{array}{c}\text { Cognitive } \\
\text { empathy }\end{array} \\
.716\end{array}$} & \multirow[t]{2}{*}{$\begin{array}{c}\text { Social } \\
\text { skills }\end{array}$} & \multirow[t]{2}{*}{$\begin{array}{l}\text { Emotional } \\
\text { reactivity }\end{array}$} \\
\hline 54 & I can easily work out what another person might want to talk about. & & & \\
\hline 52 & I can tune into how someone else feels rapidly and intuitively. & .695 & & \\
\hline 58 & I am good at predicting what someone will do. & .683 & & \\
\hline 55 & I can tell if someone is masking their true emotion. & .654 & & \\
\hline 251 & I am good at predicting how someone will feel. & .633 & & \\
\hline 36 & Other people tell me I am good at understanding how they are feeling and what they are thinking. & .618 & & \\
\hline 19 I & I can pick up quickly if someone says one thing but means another. & .618 & & \\
\hline 411 & I can easily tell if someone else is interested or bored with what I am saying. & .565 & & \\
\hline 441 & I can sense if I am intruding, even if the other person doesn't tell me. & .543 & & \\
\hline 261 & I am quick to spot when someone in a group is feeling awkward or uncomfortable. & .537 & & \\
\hline 81 & I find it hard to know what to do in a social situation. & & .675 & \\
\hline $21 \mathrm{I}$ & It is hard for me to see why some things upset people so much. & & .664 & \\
\hline $14 \mathrm{I}$ & I often find it difficult to judge if something is rude or polite. & & .630 & \\
\hline $4 \stackrel{i}{f}$ & $\begin{array}{l}\text { I find it difficult to explain to others things that I understand easily, when they don't understand it } \\
\text { first time. }\end{array}$ & & .538 & \\
\hline 48 & Other people often say that I am insensitive, though I don't always see why. & & & .587 \\
\hline 501 & I usually stay emotionally detached when watching a film. & & & .518 \\
\hline 271 & If I say something that someone else is offended by, I think that that's their problem, not mine. & & & .517 \\
\hline 32 & Seeing people cry doesn't really upset me. & & & .497 \\
\hline & Friendships and relationships are just too difficult, so I tend not to bother with them. & & & .483 \\
\hline $43 \mathrm{~F}$ & Friends usually talk to me about their problems as they say that I am very understanding. & & & .481 \\
\hline $6 \mathrm{I}$ & I really enjoy caring for other people. & & & .420 \\
\hline 42 I & I get upset if I see people suffering on news programmes. & & & .402 \\
\hline & Eigenvalues & 5.60 & 2.47 & 1.80 \\
\hline & Variance (\%) & 20.02 & 8.85 & 6.43 \\
\hline & Cronbach's alpha & .85 & .60 & .60 \\
\hline
\end{tabular}

Note: Extraction Method: Shaft factoring principal, to 3 factors extracted. 
easily tell if someone else wants to enter a conversation" with a skewness value of $-1.83(S D=.17)$, and kurtosis of $2.51(S D=.34)$. No items were eliminated according to the criteria used in the discriminative analysis of items (average $t=7.20, p>.05)$.

\section{Construct validity and internal consistency of the EQ}

Using the 28 original items of the EQ, the results of the equamax rotation of the items of the EQ accounted for $35.3 \%$ with a Kaiser-Meyer-Olkin sampling adequacy of .79 and a significant Bartlett test $(p<.001)$. Of the original 28 items used for the analysis, 22 were included in the factor model. Twenty items displayed adequate communalities in the original designated domains of the EQ (10 items from the Cognitive empathy dimension, seven from the Emotional reactivity dimension, and three from the Social skills dimension and are displayed in Table 1. Two items were related to a different domain. From the Emotional reactivity dimension, item 21, "It is hard for me to see why some things upset people so much," displayed communality with the Social skills dimension, while item 12 "Friendships and relationships are just too difficult, so I tend not to bother with them" from the Social skills dimension, displayed communality with the Emotional reactivity dimension.

The Cronbach's alpha coefficient for the combined 22 items was .80 . As can be seen in Table 1, high reliability was also obtained for the Cognitive empathy dimension. Nevertheless, Emotional reactivity and Social skills dimensions exhibited lower internal consistency values.

\section{Correspondence factorial analysis and congruence factor analysis}

The relations between the three dimensions of the EQ obtained in the exploratory factor analysis and the scored empathic response are shown in Figure 1. Non-empathic response had a higher contribution to the Cognitive empathy factor, while the strong empathic response was more related to the Emotional reactivity factor. The social skills factor was theoretically more related to the factor of Cognitive empathy, but responses were more related to an empathic response as observed by its proximity to the Emotional reactivity factor.

Adequate congruence coefficients were obtained between the 28-item version factors of the EQ and the factors obtained in the present study. The highest coefficient was observed in the Cognitive empathy factor $(.97, p<.001)$ followed by the Emotional reactivity factor $(.91, p<.001)$ and finally, the Social skills factor $(.89, p=.01)$. Cognitive empathy and Emotional reactivity factors are clearly differentiated and related to different empathic responses. The factor of Social skills is theoretically more related to the

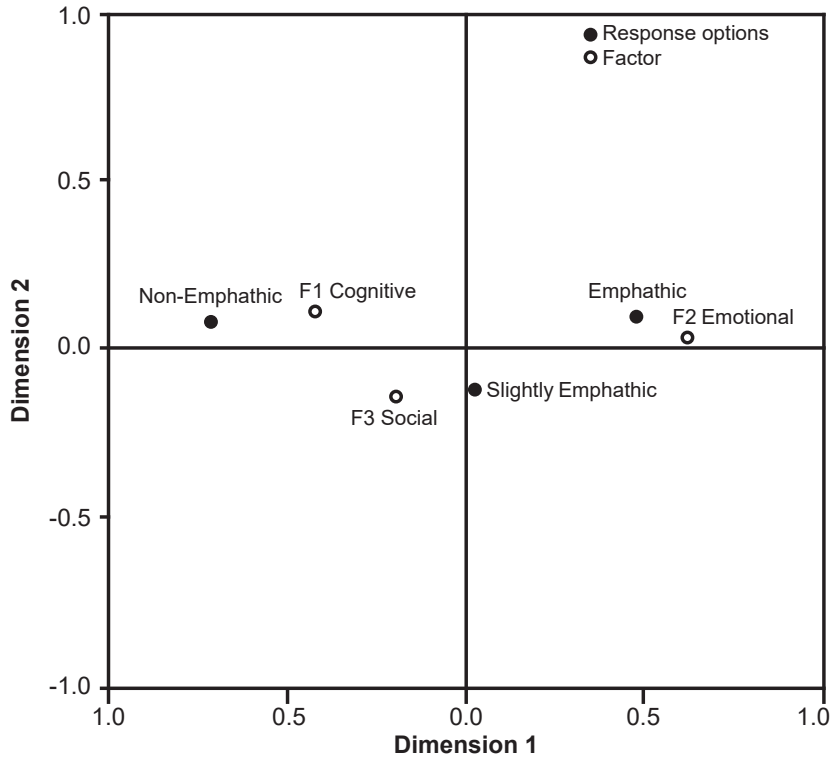

Figure 1. Correspondence factor analysis.

F1 Cognitive = Factor 1 Empathy Cognitive; F2 Emotional = Factor 2 Emotional Empathy; F3 Social $=$ Factor 3 Social Skills.

Cognitive empathy but the responses to this factor are more related to an empathic response as observed by its proximity to the Emotional reactivity factor.

\section{DISCUSSION AND CONCLUSION}

The aim of the present study was to prove the psychometric properties of the 28-item version of the EQ in a Mexican sample. Cultural adaptation of instruments is indispensable for the development of appropriate measurements according to the specific population of interest. Therefore, it is essential to have validated instruments for the Mexican population to improve research in social cognition in psychiatry and to perform further cross-cultural studies.

An adequate internal consistency (Cronbach's alpha = $.80)$ of the EQ was obtained in the present study. In similar studies, adequate internal consistency has been achieved with a reduced number of items compared to the original scale. In the Japanese version of the EQ, Wakabayashi et al. (2006) used a 22-item version and obtained a .90 Cronbach's alpha. Similar results can be found in the work of Muncer and Ling (2006) and Kim and Lee (2010) who reported the internal consistency of .84 and .78 Cronbach's alpha in a 28 -item version for the EQ scale.

Our study supports the existence of three main dimensions of empathy assessed with the EQ as those obtained by Lawrence et al. (2004), although our analysis includes only 22 of the 28 original proposed items. Cognitive empathy exhibits almost the same structure with 10 of the original 11 items proposed. Item 1 "I would be very upset if I couldn't listen to music every day," which was originally 
in this dimension was not included, possibly as it refers to a specific stimulus - music- that may play a role different to empathy in the present Mexican sample. This item, for example, loads in the Emotional reactivity factor in the Chinese validation of the EQ (Zhang et al., 2018), in the Social skills factor (with a low factor loading of .31) in the study of Lawrence et al. (2004), and is not included in the study performed by Muncer and Ling (2006). However, the remaining 10 items corresponding to the original items of this dimension explaining $20.0 \%$ of variance and with the highest reliability.

The Social skills factor, which explains $8.8 \%$ of the variance, had important differences when compared to the 28 -item version of the EQ. Our factor analysis just includes three of the six items (item 4, item 8 and item 14). Item 35 "I don't tend to find social situations confusing" and item 57 "I don't consciously work out the rules of social situations" displayed loadings lower than the threshold of .40 and were not included in the model. Item 57 was also not included in the Chinese validation of the EQ by Zhang et al. (2018) and neither in the 28-item version of the EQ (Lawrence, 2004); this item displayed low factor loadings (.39). Nevertheless, this item, as well as item 35 were adequately located in the Social skills factor in other studies. Additionally, item 21 "It is hard for me to see why some things upset people so much," originally displayed in the Emotional reactivity factor, loaded in the Social skills factor in a Mexican population. The Cronbach's alpha for the Social skills factor was .60 which is lower but may be considered still acceptable given that this factor only has four items.

Similarly according to what was observed in the Social skills factor, two items of the Emotional reactivity factor, item 22 "I find it easy to put myself in somebody else's shoes" and item 29 "I can't always see why someone should have felt offended by a remark," displayed loadings lower than .40 a result also observed in the study of Lawrence et al. (2004), where these items showed loadings of .38 and .33 , respectively; thus, the fact that they have not been included in any dimension of the factorial analysis is to be expected. Also, item 12, "Friendships and relationships are just too difficult, so I tend not to bother with them," loads on this factor and not in the Social skills factor as originally stated. We assume that words such as friendship and relationships may evoke an emotional meaning more than a social meaning for individuals in our sample and may be the reason why this item load in this dimension. Although the Cronbach's alpha for this dimension is equal to the one obtained in the Social skills dimension (.60); this value should be considered as inappropriate for internal consistency as this dimension comprise eight items.

Much of what is observed in the factor analysis can be explained with the results of the correspondence analysis. As can be seen, the Cognitive empathy factor is clearly separated from the other two factors and is related to a non-empathic response. However, even the Social skills and the Emotional reactivity factors are theoretically separated from each other, and it seems that individuals respond to these factors in a more empathic and similar way, leading to what can be considered as an affective response. Therefore, we hypothesize that, for Mexican population, a mixed meaning of the items of these two dimensions may cause these inconsistencies due to cultural setting and that they should be studied further in other samples and with a confirmatory factor analysis.

Despite the above, the present version of the EQ, comprising 22 items, exhibits high congruence coefficients $(>.85)$ with the 28-item version of the scale which means that both instruments evaluate the three dimensions of empathy in a similar way. However, the low internal consistency reported in the Social skills and Emotional reactivity dimensions emphasize the need for additional studies of these dimensions and how items are constructed to assess these important components related to empathy.

Despite the limitations found with these dimensions, we conclude that this first approach to validate the EQ show its adequacy for its use in Mexican population as the 22-item version of the EQ showed a global high reliability, consistency, and congruence with the proposed factor structure. Another limitation regarding our sample is the probable bias that can be observed in terms of sex, age and, education, where more than half of the recruited individuals were women, no information regarding educational status was obtained, and the wide age range of recruited participants. Therefore, the use of the EQ should be taken with caution considering these limitations.

\section{Funding}

None.

\section{Conflicts of interest}

The authors declare they have no conflicts of interest.

\section{Acknowledgements}

Saracco-Alvarez R., appreciates the support of Programa de Maestría y Doctorado en Ciencias Médicas, Odontológicas y de la Salud de la Universidad Nacional Autónoma de México.

\section{REFERENCES}

American Psychiatric Association. (2000). Diagnostic and Statistical Manual of Mental Disorders (4th Edition, Text Revision), DSM-IV-TR. Washington DC: American Psychiatric Association. doi: 10.1176/appi.books.9780890423349

Baron-Cohen, S., Richler, J., Bisarya, D., Gurunathan, N., \& Wheelwright, S. (2003). The systemizing quotient: An investigation of adults with Asperger syndrome or high-functioning autism, and normal sex differences. Philosophical Transactions of the Royal Society of London. Series B: Biological Sciences, 358(1430), 361 374. doi:10.1098/rstb.2002.1206

Baron-Cohen, S., \& Wheelwright, S. (2004). The empathy quotient: An investigation of adults with Asperger syndrome or high functioning autism, and normal sex differences. Journal of Autism and Developmental Disorders, 34(2), 163-175. doi:10.1023/b:jadd.0000022607.19833.00 
Baron-Cohen, S. (2012). The science of evil: On empathy and the origins of cruelty. Basic books.

Berthoz, S., Wessa, M., Kedia, G., Wicker, B., \& Grèzes, J. (2008). Cross-cultural validation of the empathy quotient in a French-speaking sample. The Canadian Journal of Psychiatry, 53(7), 469-477. doi:10.1177/070674370805300712

Davis, M. H. (1983). Measuring individual differences in empathy: Evidence for a multidimensional approach. Journal of Personality and Social Psychology, 44(1), 113-126. doi: 10.1037//0022-3514.44.1.113

Escrivá, V. M., Navarro, M. D. F., \& García, P. S. (2004). La medida de la empatía: análisis del Interpersonal Reactivity Index. Psicothema, 16(2), 255-260. Retrieved from https://www.redalyc.org/pdf/727/72716213.pdf

Farrow, T. F. (2007). Neuroimaging of empathy. In: Farrow, T., Woodruff, P. Empathy in Mental Illness (1st Edition), (pp. 201-216). London: Cambridge University Press. Retrieved from http://gamut.neiu.edu/ 1ruecker/Farrow.pdf

Jankowiak-Siuda, K., Kantor-Martynuska, J., Siwy-Hudowska, A., Śmieja, M., Dobrołowicz-Konkol, M., Zaraś-Wieczorek, I., \& Siedler, A. (2017). Psychometric properties of a Polish adaptation of short form of the Empathy Quotient (EQ-Short). Psychiatria Polska, 5l(4), 197-734. doi: 10.12740/ $\mathrm{pp} / 64270$

Kim, J., \& Lee, S. J. (2010). Reliability and Validity of the Korean Version of the Empathy Quotient Scale. Psychiatry Investigation, 7(1), 24-30. doi: 10.4306/ pi.2010.7.1.24

Lamm, C., Batson, C. D., \& Decety, J. (2007). The neural substrate of human empathy: effects of perspective-taking and cognitive appraisal. Journal of Cognitive Neuroscience, 19(1), 42-58. doi: 10.1162/jocn.2007.19.1.42

Lawrence, E. J., Shaw, P., Baker, D., Baron-Cohen, S., \& David, A. S. (2004). Measuring empathy: Reliability and validity of the Empathy Quotient. Psychological Medicine, 34(5), 911-920. doi: 10.1017/s0033291703001624

Leiberg, S., \& Anders, S. (2006). The multiple facets of empathy: A survey of theory and evidence. Progress in Brain Research, 156, 419-440. doi: 10.1016/s00796123(06)56023-6

Marsh, A. A. (2018). The neuroscience of empathy. Current Opinion in Behavioral Sciences, 19, 110-115. doi: 10.1016/j.cobeha.2017.12.016

Moore, R. C., Dev, S. I., Jeste, D. V., Dziobek, I., \& Eyler, L. T. (2015). Distinct neural correlates of emotional and cognitive empathy in older adults. Psychiatry Research: Neuroimaging, 232(1), 42-50. doi: 10.1016/j. pscychresns.2014.10.016

Muncer, S. J., \& Ling, J. (2006). Psychometric analysis of the empathy quotient (EQ) scale. Personality and Individual Differences, 40(6), 1111-1119. doi: 10.1016/j. paid.2005.09.020
Nunnally, J. C. (1994). Psychometric theory 3E. New York: Tata McGraw-Hill Education.

Pan, Y., \& de la Puente, M. (2005). Census Bureau guideline for the translation of data collection instruments and supporting materials: Documentation on how the guideline was developed. Survey Methodology. 6. Retrieved from https:// www.census.gov/content/dam/Census/library/working-papers/2005/adrm/ rsm2005-06.pdf

Perry, A., \& Shamay-Tsoory, S. (2013) Understanding emotional and cognitive empathy: A neuropsychological perspective. In Baron-Cohen, S., TagerFlusberg, H., \& Lombardo, M. (Eds.), Understanding other minds: Perspectives from developmental social neuroscience, (pp. 179-194). United Kingdom: Oxford University Press. ISBN 9780199692972

Pijnenborg, G. H. M., Spikman, J. M., Jeronimus, B. F., \& Aleman, A. (2013). Insight in schizophrenia: Associations with empathy. European Archives of Psychiatry and Clinical Neuroscience, 263(4), 299-307. doi: 10.1007/s00406-012-0373-0

Preti, A., Vellante, M., Baron-Cohen, S., Zucca, G., Petretto, D. R., \& Masala, C. (2011). The Empathy Quotient: A cross-cultural comparison of the Italian version. Cognitive Neuropsychiatry, 16(1), 50-70. doi: 10.1080/13546801003790982

Reyes-Lagunes, I., \& García y Barragán, L. F. (2008). Procedimiento de validación psicométrica culturalmente relevante: un ejemplo. In La Psicología Social en México, 12, (pp. 625-636).

Sheehan, D. V., Lecrubier, Y., Sheehan, K. H., Amorim, P., Janavs, J., Weiller, E., ... Dunbar, G. C. (1998). The Mini-International Neuropsychiatric Interview (MINI): The development and validation of a structured diagnostic psychiatric interview for DSM-IV and ICD-10. The Journal of Clinical Psychiatry, 59(Suppl 20), 22-33.

Wakabayashi, A., Baron-Cohen, S., Wheelwright, S., Goldenfeld, N., Delaney, J., Fine, D., ... Weil, L. (2006). Development of short forms of the Empathy Quotient (EQ-Short) and the Systemizing Quotient (SQ-Short). Personality and Individual Differences, 41(5), 929-940. doi: 10.1016/j.paid.2006.03.017

Wrigley, C., \& Neuhaus, J. O. (1955). The matching of two sets of factors (Contract Report No. A-32, Task A). Urbana, Illinois: University of Illinois.

Zaki, J., \& Ochsner, K. (2013) Neural sources of empathy: An evolving story. In Baron-Cohen, S., Tager-Flusberg, H., \& Lombardo, M. (Eds.), Understanding other minds: Perspectives from developmental social neuroscience. (pp. $215-$ 232). United Kingdom: Oxford University Press. ISBN 9780199692972

Zhang, Y., Xiang, J., Wen, J., Bian, W., Sun, L., \& Bai, Z. (2018). Psychometric properties of the Chinese version of the empathy quotient among Chinese minority college students. Annals of General Psychiatry, 17(1), 38. doi: 10.1186/s12991-018-0209-z 